\title{
The Dialectics of Humanism and Pragmatism as a Basis for the Formation of Higher Education Strategy Development
}

\author{
Serhii Terepyshchyi \\ Doctor of Philosophical Sciences, Professor, National Pedagogical Dragomanov University \\ (Kyiv, Ukraine) \\ E-mail: terepyshchy@gmail.com \\ https://orcid.org/0000-0001-5506-0914
}

\section{Hleb Khomenko}

Junior Research Fellow, Ph.D. Student (Philosophy), National Pedagogical Dragomanov University (Kyiv, Ukraine)

E-mail: homenkoglib@gmail.com

https://orcid.org/0000-0003-2897-5400

Terepyshchyi, Serhii and Hleb Khomenko (2019) The Dialectics of Humanism and Pragmatism as a Basis for the Formation of Higher Education Strategy Development. Ukrainian Policymaker, Volume 5, 98-107. https://doi.org/10.29202/up/5/11

This article is an attempt to analyze the key contradictions between humanistic and pragmatic orientations in the modern space of higher education. The authors use a philosophical approach in understanding the value of knowledge as a powerful tool for social and economic development. It has been proved that politicians and teachers play almost the same role in overcoming the global poverty and violence. Instead of theorizing about humanistic ideals, they should direct the ideas of humanism in a practical way - through the training of students and the creation of a favorable climate for the life of citizens. The ideas of democracy and human respect must also go beyond the audience and be implemented in the practical dimensions of society. Science in universities must be subordinated to humanistic values, just as philosophy was subordinated to Theology in the Middle ages. While most universities are trying to mobilize efforts to increase economic performance, it is necessary to work on the development of intellectual capital in society. In addition, it is important for policy makers to understand the difference between the training of a competitive specialist and the education of a harmonious personality in the context of the formation of a higher education strategy. These processes must occur synchronously and not contradict each other. That is why the study of philosophy or cultural studies is no less important than the study of mathematics and physics. In addition, the language of the world is defined not only as a certain lexical set that a person

(C) Terepyshchyi, Serhii, 2019

(C) Khomenko, Hleb, 2019 
The Dialectics of Humanism and Pragmatism as a Basis for the Formation of Higher Education Strategy Development by Serhii Terepyshchyi and Hleb Khomenko

can possess, but also rather as a set of inherent knowledge and values that a person constantly implements in relationships with other people.

Keywords: humanism, pragmatism, peacebuilding, social conflict, poverty, higher education

Received: October 4, 2019; accepted: December 1, 2019

\section{Introduction}

One of the main dilemmas of a philosophical nature in the formation of a strategy for the development of higher education at the present stage is the dialectic of humanistic and pragmatic orientations. To find the optimal balance in the dichotomy of these principles, one should try to answer the age-old question formulated by one of the founders of philosophical thought - the Greek thinker Aristotle. The content of this question is as follows: is knowledge of absolute value, or is it valuable only in the context of achieving a person's practical goals, pursuing a specific activity in a real dimension? Many philosophers have tried to answer this question on the basis of their own ideological and value principles, based on the "spirit of the era", as well as on other objective factors.

A sufficiently detailed and rationally reasoned answer to the above question was found in the works of the German philosopher, statesman Wilhelm von Humboldt, who was forever rooted in the history of his nation's higher education as a progressive reformer, as well as the founder of the University of Berlin.According to Humboldt, the university is a tool for bringing people together who profess the values of intellectual freedom and peace while supporting a unified research lifestyle. There can be no doubt that the activities of the first European universities, which appeared in the Middle Ages, were based on such philosophical principles. It is known that the first universities in the classical sense were the educational centers of Bologna, Oxford and Cambridge.

Over time, the socio-cultural role of the University has undergone certain changes, but in any case, this hasn't negated its main goal — to generate qualitatively new knowledge for social progress and improvement of human living conditions.It is obvious that the functioning of universities in the today's dimensions is devoid of the idealism that was inherent in the earlier stages of society. Modern higher education institutions are deprived of the right to freethinking, going beyond the existing paradigm of thinking, since their funding is provided by the profile ministry, i.e.the direct executive body in the state. In this case, one can recall the famous British expression, "He who pays the piper calls the tune". In the context of a permanent economic crisis in the world, it remains for universities to mobilize the available resources to preserve their integrity, forgetting about their eternal mission of spiritual enrichment of society by popularizing humanistic values.

The irrelevant value of the humanitarian knowledge of Antiquity and Modern times in the modern era is being replaced by the relative value attached to pragmatic epistemology. This is particularly evident in the current administrative reforms in the European educational space, where the emphasis of idealistic freedom in higher education and science is shifting towards instrumental "freedom for".As the modern Greek researcher Andreas Casamias notes, "the EU Discourse on education and training is imbued with an instrumentalistic ethos that views knowledge and culture as a means to achieve economic goals"(Kazamias, 2010: 32). Just on such specific pragmatic grounds, that consider the Humanities as a cognitive and productive 
tool, the modern ideal of the European educational policy, called ambitiously the "knowledge society", is based (Kazamias, 2010: 32).

As it was pointed out by one of the authors of this article in the previous research, modern society is a complex system of implicit and explicit links, which are conditioned by two major transhistorical factors - the authority of social tradition and the objective necessity of a particular era. Against the backdrop of the collision of these diachronic forces, there is a change in the surrounding reality, which has long dragged the conservative and progressive elites into the conflict. The present time is not exceptional, and even more so, the conflict of values of the past and the present has grown on a global scale, embodying almost all spheres of humanity. This applies to the confrontation of globalists and anti-globalists, advocates of centrism of the national economy and economic cosmopolitans», traditionalists and postmodernists, religious fundamentalists and spiritual liberals, fans of modern art and apologists of art classics, etc. (Terepyshchyi, 2016: 85-86). Education also does not remain outside the outlined conflict, which only increases the relevance of the analysis of this problem.

As rightly noted by the Ukrainian philosopher Sergei Proleiev, "education as a social institution contains a threatening ambivalence. On the one hand, it offers the human person access to the cultural achievements of mankind and opens up opportunities for productive development of the individual, building a creative and successful life scenario. On the other hand, the educational process decomposes and destroys the original personality, produces people for a given social system, re-forms them into typical social characters for a given society. The social system tends to its reproduction simply through the educational system. Thus, it seeks to preserve the stable dispositions of social relations, a set of social roles and a hierarchy of values" (Proleiev, 2007:18). Such a statement gives reason for deep reflection not only to scientists and philosophers, but also to politicians who must realize the severity of this problem and its ambiguous impact on the development of modern society.

When going to University to work or study, everyone should be honest with himself, answering the question-what is the ultimate goal of my activity? It would be naive to think that a large percentage of today's students will choose to neglect the acquisition of professional skills for the sake of something that will in no way bring them closer to success in the later stages of life. According to Lex Borghans and Frank Cörvers, for example, in the Netherlands, more and more young people prefer higher professional institutions where they teach practical skills without combining science with the educational process. Since 1985, the number of students in Dutch society has ceased to increase, but the growth of the number of people studying in higher professional institutions has significantly intensified. This process is a kind of litmus test, clearly demonstrates the obsolescence of the classical University in the socioeconomic context, which pushed European officials to the American course of reforms. After all, this was almost the only way to rehabilitate the pragmatic component of the existence of education, its return to the real economic world (Borhans \& Cörvers, 2010: 19-20).

The essence of the European University is the indissoluble unity of different pragmatic purposes, which makes it "obsolete" in the modern strictly functional system. As Karl Jaspers rightly pointed out in his work "The Idea of a University","a University is a professional school, a world of learning, a research institution. Between these three possibilities there is an "either-or" and the question is raised: what is actually wanted from the University, after all, it cannot decide everything, it should define one goal for itself. In this latter sense, it is in demand the elimination of the University, and instead of it the formation of special professional schools, educational schools (in the form of special faculties that should serve only education) and 
research institutions. However, in the idea of the University, these goals form an indissoluble unity. One goal cannot be separated from the others without destroying the spiritual essence of the University and at the same time destroying itself" (Jaspers, 2006: 66).

There can be no doubt that this trend is not unique to the European socio-cultural space. In particular, in August 2015, by the decision of the Japanese government, the Departments of Humanities were eliminated in most national universities. Politicians explain this decision by the fact that these units are "unnecessary" for the development of the country (Grove, 2015). The Japanese education system has long adopted the American pattern of education for economic development. The partial elimination of humanitarianism from the structure of the educational system is, in fact, a radical way to accelerate the process of pragmatization of education, its compliance with the international model. Indeed, humanitarian education and sciencerespond to external transformations too slowly, it is a kind of "ballast" of the innovation movement. On the other hand, it is difficult to overestimate the role of the disciplines of the humanitarian cycle in the processes of solving acute social conflicts within a society that suffers from a lack of understanding at the ideological and value level. It is one thing to teach a student how to solve a particular problem in a math class, it is quite another to cultivate a humanistic - oriented personality in this person. Both the first and the second require high pedagogical skills, an individual approach to each applicant for education and a sincere desire of the teacher to make the world a better place by training each student. Many scientists have focused already in their works on the fact that higher education as a tool for peacebuilding is significantly underestimated (Milton \& Barakat, 2016; Novelli \& Smith, 2011; Pacheco \& Johnson, 2014; Svyrydenko, 2019). The content of these scientific publications is the theoretical and methodological basis for this article. In the following paragraphs, it is proposed to elaborate on the philosophical analysis of certain works, entering into a kind of academic discussion with its authors.

\section{Theoretical and methodological framework of the research}

The main methods used in the process of preparing the manuscript of this article scientific reflection, deduction and abstraction, gave the authors the opportunity to carry out a thorough analysis of the original sources listed below and get their own non-standard, original conclusions. First of all, it should be staredt with the understanding of the key ideas of Sansom Milton and Sultan Barakat, which are of great importance in the context of writing this work, because it pursues the identical task - to eliminate gaps in the understanding of the impact of higher education on society in conflict.

The authors suggest several directions where the universities should move in full consolidation-stabilization and securitization, reconstruction, state-creation and peacebuilding. Together, they form a single system that focuses on strengthening state structures, restoring people's trust in government, and respect for members of society to each other. Based on the study of individual cases of various military conflicts from Bosnia and Herzegovina to Sierra Leone, scientists emphasized aptly that the intelligentsia, scientific and pedagogical staff of universities hadbeen often subjected to harassment and outright bullying, which significantly "tied their hands" in the dissemination of humanistic values (Milton \& Barakat, 2016). When the question is about a crisis at the level of academic freedom and intellectual capital, it becomes obviousthat the material and technical base in universities is even more neglected. 
It is impossible to ignore the fact that sometimes higher education causes even more harm to post-conflict rehabilitation of society, when instead of calling people to reconciliation, it reflects all negative phenomena that are inherent in a certain society as a whole - interracial or interreligious hostility, segregation, conflict of political ideologies, and so on. As a confirmation I would like to quote:"However, higher education can in some contexts have negative socialisation effects that work counter to reconciliation and conflict transformation. For instance, during and after conflict universities in Bosnia and Lebanon became split along confessional lines. In these cases, higher education institutions reflect the social context of conflict and function as perpetuators of conflictual identities rather than as arenas of social transformation. In another case, in response to post-war violence in Iraq - which escalated in 2005 and peaked in 2007 - many faculty members were killed, threatened, and harassed often for their ascribed identity. As a result, university staff left their posts and displacement of academics occurred along ethno-sectarian divides. Individual universities came to be associated with sectarian and political divides. For example, Al-Mustansiriya was perceived as a Shiite institution while Al-Nahrain was seen as a Sunni institution. Once "mixed" universities such as Basra and Mosul came to be relatively homogeneous. While this de facto separation positively influenced the short-term security of campuses, the "ethnic enclave" model has been less beneficial in contributing to long-term peacebuilding goals of overcoming conflict through promoting inter-communal understanding and social cohesion" (Milton \& Barakat, 2016: 414).Therefore, sometimes higher education is also able to throw its negativeness into the center of the conflict, contributing nothing to mutual understanding between people, but rather the opposite. Therefore, in our opinion, timely consensus-building within universities and their collective decision-making in the context of the development of higher education as a tool for transforming the dominant triggers of conflict and peace-building is crucial thing in this case.

A thorough understanding of the scientific article by Ivan Pacheco and Turner Johnson is useful for our work, because it is a comparative analysis of two seemingly non-identical conflict situations in Colombia and Kenya, and on the basis of this, specific proposals are made to determine the architecture of the world-wide processes for the participation of educational stakeholders. The authors propose to consider peace building not only as a situational perspective in the development of the educational industry, but also as a permanent vector of stabilization of society: "Peacebuilding, as a role of higher education, must be more than just a reaction to conflict, it must be infused into the purpose of higher education in fragile states. Providing opportunities to universities to play a role in peacebuilding an funding university activities in conflict abatement may contribute to a new discourse and sustainable responses to violence" (Pacheco \& Johnson, 2014: 6). Except it, they compared various initiatives of higher education institutions and ranged them on the indexes of the productivity.

It is worth adding that the performance of universities and other institutions of higher education in the context of peace-building does not depend on the signing of inter-state agreements at the political and diplomatic level.Scientific and pedagogical staff of higher educational institutions can always promote a dialogue method of communication in society, conduct various trainings and master classes to disseminate modern methods of overcoming conflicts, develop critical thinking, reduce the unemployment rate by means of higher education, promote the demobilization of combatants, and provide psychological assistance in refugee camps, even if this is not provided at the legislative level. After all, it is well known that in emergency situations, the worst thing is to delay and wait for the command "from 
above”. By the way, in previous studies, the authors of this article have already developed a certain method of non-violent interaction in the academic environment, which can be found in the open access at the specified link (Terepyshchyi \& Khomenko, 2019] .

Continuing the presentation of this work, it should be noted that the content of the prepared document with the participation of Mario Novelli and Alan Smith interests us in that it offers an original vision for the creation of educational programs and implementation of various educational initiatives that would strengthen the activities of the UN in laying a solid and reliable Foundation for further peace-building. Novelli and Smith make it clear that the education sector cannot continue to remain on the periphery of society in emergency conditions: "Crucially, education is not a marginal player in peacebuilding, but a core component of building sustainable peace. Peacebuilding is essentially about supporting the transformative process any post-conflict society needs to go through and these change processes unfold over generations. In the short to medium term, external peacebuilding support is aimed at assisting the society to develop the resilience needed to prevent a lapse into violent conflict, and in the medium to longer term the emphasis shifts to developing the resilience needed for selfsustainable peace" (Novelli \& Smith, 2011: 37).

Moreover, we support the idea that education in the educational sphere should begin at the value level. Unbiased educational experts and scientists should jointly analyze what values are translated within the national educational system and on what philosophical principles one or anothereducational model is based. In our opinion, it is important that it is dominated by centripetal rather than centrifugal tendencies. This will be the first really significant step towards a harmonious society in which violence can only be encountered on the pages of individual textbooks ormanuals.

The authors of the last but no less important work, which will be discussed now, are Denys Svyrydenko, Chengzhang Zou ta Weizhen Gao. Their article is devoted to the consideration of higher education as a tool for peace-building and decolonization on the example of the situation in Ukraine. The authors scientifically prove that the design of a progressive educational policy in the field of peace-building requires a critical study of international experience, the IsraeliPalestinian conflict, in particular. However, blind borrowing of foreign practices is absolutely destructive phenomenon that can lead to the formation of a false trajectory in the development of society. No less important one is the proposal of scientists to create separate training modules in universities within the existing disciplines: "It is advisable to develop a model program for peacebuilding for students of all specialties. Taking into account international experience (schools of peace, education camps for peace, etc.), there is a need for the introduction of a special training course on the foundations of peacebuilding in universities. Also, it is necessary to offer separate educational modules in the curriculum of disciplines: "Politics", "Law", "History of Ukraine", "Philosophy", "Philosophy of education", "Educational policy", etc. These modules for existing programs on various humanitarian disciplines will increase the reach of potential participants in the peacebuilding process. The proposed changes in the content of education will comprehensively cover the problems of internally displaced persons, mediation, nonviolent interaction, education of tolerance, opposition to propaganda, development of critical thinking, etc." (Svyrydenko, et al., 2019: 53). It is not surprising that the vast majority of the disciplines proposed here are the part of a unite complex called humanitarianism. 


\section{Discussion}

Taking into account the previous opinions and views of scientists, we should return to the main dilemma in this work - the correlation of humanistic and pragmatic orientations in the context of choosing a successful trajectory of higher education development. As it has been emphasized in the previous part of this work, it is impossible to neglect the humanistic component of higher education in any case, because now we are talking about the future of civilization by educating new generations of the progressive-minded young people. It is obvious that the University should be focused on the needs of society, namely its economic and socio-cultural dimensions. However, we cannot allow the University to be downplayed as a "factory of professions" or, even worse, as a "factory of diplomas".

In this context, it is advisable to pay attention to the reflections of the British scientist Michael Gibbons, who believes that the changes taking place in the academic space of Europe are natural and areconsequences of a key factor in the university crisis- massification of the studies. "Massification is due to the fact that the university departmentshave been the main places of scientific development. But more and more often in our era, researchesare also being carriedout in other places, in particular, such asdifferent enterprises". This, in turn, leads to natural changes that deprive the University of the privileged status of a scientific monopoly and put the latter in a situation of typical capitalist competition (Gibbons, 1994: 76).

We like the position of some postmodernist theorists in education, according to whom the University must meet the social situation that surrounds it in order to realize both humanistic and pragmatic goals. It can no longer be the standard of the detached "unselfishness" that is promoted in Humboldt's ideas and must accept the necessary social role and laws of the market.This view, in particular, is supported by the British researcher Peter Scott, who also notes that the university should expand its functions to an institution engaged in life-long learning and even leisure (Scott, 1997). Because of this, at any cost, universities should maintain the teaching of Humanities, which are focused not so much on practical skills as on the development of personal worldview. After all, their goal is not to train, say, philosophers, cultural scientists, but rather to spread humanistic values in society to a wide range.

Moreover, we are convinced that students of higher educational institutions should study both fundamental and applied Sciences. This will help in expanding the horizons of their thinking, which will focus on constructive actions and activities, operating by the language of peace, not by the language of war. The language of the peace means not only a certain vocabulary that a person can possess, but rather a set of inherent knowledge and values that it represents in relations with other people, carriers of non-identical life principles. It is important to emphasize that knowledge of the language of the peace in the dimensions of modernity requires a high level of intelligence and intellectuality, which is manifested in respect for other people regardless of their skin color, ethnic origin, religious or political position. After all, history has known many cases when extremely intelligent and educated people, having received power, lost their minds, a persistent sense of the earth under their feet, condemning individual Nations and States to genocide, collective suicide, and so on.

Today, many educators proclaim child-centrism and human-centrism, but these slogans are only manifested in the fact that teachers put the success of their work in dependence on the success of students, but they do not set themselves the goal to cultivate the desire for selfsufficiency. The education of this trait would not only help in combating the many problems and doubts of pupils and students (inferiority complex), but it would also help in establishingthe 
true subject-subject relations in the pedagogical communication between teacher and student, professor and student, it will form an important platform for the development of a responsible and democratic society of a new type in which politicians will fulfill the will of the citizens exclusively, forgetting about personal interests, but remembering the interests of the state. To some extent, this statement may be perceived as too idealistic, but it is an important point of support in political decision-making.

A teacher, like a politician, must not only speak eloquently about humanistic values in front of an audience of his listeners, but also reproduce them in their own actions in relation to members of society. Betty Reardon, Director of the higher education program at the center for peace and peaceful education at Columbia University's teachers College, points out that teachers and politicians must share a common goal: to maintain peace on a local and global scale, to respect the rights of each individual, and to allow him to find his place in society. In one of her most fundamental work, the American researcher argues that achieving peace requires the elimination of such negative phenomena as sexism, racism, nationalism, poverty, elite education, militarism, etc. (Reardon, 1988). On this basis, the effectiveness of the national strategy for the development of higher education as a tool for peace-building should be evaluated, taking into account the presence or absence of these phenomena in the educational sector. Because if nationalism takes place in the educational sector, it cannot be eradicated from the society itself.

The same applies to refugees, who should get a chance to integrate into a certain social community through the educational space. In particular, Jacqueline Mosselson, rightly points out that "education creates a space in which a refugee can retreat from the labels of "exotic" or "alien", one becomes a "student", at the same time experience silences their refugee status. Refugees often talk about how others viewed them as different, which caused a sense of unease and anxiety that was directed at them by teachers during the first few months after resettlement. Over time, as they studied longer and became more integrated into the University space, they no longer described the wary attitude of classmates and teachers; once seen, they were perceived already as students, not as refugees" (Mosselson, 2011: 16). The ability of education to assimilate cultures, to create conditions for the emergence of tolerance and dialogue is one of the significant auxiliary functions in the modern post-globalization world.

If the classical University of the Old World was based on the justification of the ideology of the national state, in modern transnational conditions, educational institutions are already based on General planetary social myths. The following rhetoric is evident in the text of the Yerevan communique (May 2015): "We will support the efforts of higher education institutions to develop intercultural understanding, critical thinking, political and religious tolerance, gender equality, democratic and civic values to strengthen European and global citizenship and lay the Foundation for inclusive societies" (YerevanCommunique, 2015). Such a definition of the key directions of higher education development shows that in the modern world it is impossible to focus only on humanistic or pragmatic values, because this will inevitably lead to an imbalance, the growth of crisis phenomena in society.

One of these phenomena, which I would like to dwell on separately, is increasing poverty, caused, among other things, by disproportionate access to the resources of the world around us. While the citizens of some countries of the European continent have a high level of material well-being, intellectual development and remain optimistic about the future of their children, in other societies there is actual genocide and outright discrimination of the population. It is not surprising that permanent poverty leads to an increase in violence within individual 
countries, since weapon in this case is a symbol of mistrustof the local population in relation to the authorities and hatred of the oligarchic clans that used to parasitize on the consumption of the economic goods. If one looks at the past from the perspective of the present, it can be seen that in war, as a rule, the socially disadvantaged segments of the population are killed, while the political elite only enriches its fortune. It is obvious that without a change in this trend, there is no point in even hoping for a peaceful resolution of existing conflicts.

We firmly believe that the main value of education in modern society is to overcome the spiritual and material poverty of mankind. We assume that it is impossible to implement this intention within a single state, which means that politicians and educational diplomats should unite with each other and provide concrete proposals at the international level to solve this problem. Higher education should also be involved in this process, as a tool for the development of critical thinking, collective spirit and solidarity of the entire world community.

\section{Conclusions}

Thus, in forming the strategy for the development of higher education, it is necessary to avoid extremes regarding the correlation of humanistic and pragmatic orientations, despite the harsh realities of the modern world. Universities must be ready to prepare simultaneously new generations of young people for the unstable economic situation, instilling deep humanistic ideals, as well as provide them with the opportunity to acquire practical skills that will become possible in the subsequent stages of life. The scientific component in universities should generate new knowledge focused on solving current social problems, accustoming education applicants to comprehensive, critical thinking. If earlier in higher educational institutions it was possible to observe a kind of confrontation between "physicists" and "lyricists", today this makes no sense. Scientists should unite in order to develop a common "road map" in the direction of overcoming poverty, various forms of human discrimination, conflict-prone society. Therefore, every scientific research must become not only practically deterministic, but also humanistically oriented.

\section{References}

Borhans, Lex (2010) Americanization of European higher education and science, edited by L. Borhans and F. Kërvers. Questions of education, Vol. 2, 19-20. (in Russian)

Gibbons, Michael (1994). The New Production of Knowledge. The Dynamics of Science and Research in Contemporary Societies, London: SAGE Publications.

Grove, Jack (2015). Social sciences and humanities faculties 'to close' in Japan after ministerial intervention, Times higher education, https://www.timeshighereducation.com/news/ social-sciences-and-humanities-faculties-close-japan-after-ministerial-intervention

Jaspers, Karl (2006). The idea of university, translated from Germanby T. Tiahunova. Mynsk: Nauka.

Kazamias, Andreas (2010). The Owl of Athena: Reflective Encounters with the Greekson Pedagogical Eros and the Paideia of the Soul (Psyche), Changing Educational Landscapes, edited by D. Mattheou, Athens: Springer. https://doi.org/10.1007/978-90481-8534-4_2

Milton, Sansom, and Sultan Barakat (2016). Higher education as the catalyst of recovery inconflict-affected societies. Globalisation, Societies and Education, Vol. 14 (3), 403421. https://doi.org/10.1080/14767724.2015.1127749 
Mosselson, Jacqueline (2011). Conflict, EducationandIdentity. Conflict \& Education,Vol. 20, 10-22.

Novelli, Mario, and Alan Smith (2011).The Role of Education in Peacebuilding: A synthesis report of findings from Lebanon, Nepal and Sierra Leone, New York: UNICEF.

Pacheco, Ivan, and Turner Johnson (2014). Higher Education Conflict and Postconflict Conditions: Colombia and Kenya. International Higher Education, 1-8. https://doi. org/10.6017/ihe.2014.74.5463

Proleiev, Serhii (2007). Repression of Education: Forced Necessity or Socium's Power Intentions? Philosophy of education, Vol. 1 (6), 15-20. (in Ukrainian)

Reardon, Betty (1988). Comprehensive Peace Education: Educating for Global Responsibility, London: Teachers College Press.

Scott, Peter (1997). The Postmodern University? Contested Visions of Higher Education in Society. London: Buckingham, 39-62.

Svyrydenko, Denys, Chengzhang Zou, and Weizhen Gao (2019). Higher education as a tool of peacebuilding and decolonization: Ukrainian case and global perspective. Educational discourse, Vol. 14 (6), 45-54. https://doi.org/10.33930/ed.2019.5007.14 (6)-4

Terepyshchyi, Serhii, and Hleb Khomenko (2019). Development of Methodology for Applying Non-Violent Conflict Resolution in Academic Environment. Future Human Image, Volume 12, 94-103. https://doi.org/10.29202/fhi/12/8

Terepyshchyi, Serhii (2016). Modern educational landscapes .Kyiv: Phoenix (in Ukrainian) Yerevan Communique (2015). Ministerial Conference and Fourth Bologna Forum. http:// bologna-yerevan2015.ehea.info/files/YerevanCommuniqueFinal.pdf 